\title{
Phyllosticta musarum Infection-Induced Defences Suppress Anthracnose Disease Caused by Colletotrichum musae in Banana Fruits cv 'Embul'
}

\author{
C. L. Abayasekara ${ }^{1 *}$, N. K. B. Adikaram ${ }^{1}$, U. W. N. P. Wanigasekara ${ }^{1}$ and B. M. R. Bandara ${ }^{2}$ \\ ${ }^{l}$ Department of Botany, ${ }^{2}$ Department of Chemistry, University of Peradeniya, Peradeniya 20400, Sri Lanka \\ (Received on June 15, 2012; Revised on September 17, 2012; Accepted on October 19, 2012)
}

\begin{abstract}
Anthracnose development by Colletotrichum musae was observed to be significantly less in the fruits of the banana cultivar 'Embul' (Mysore, AAB) infected with Phyllosticta musarum than in fruits without such infections. Anthracnose disease originates from quiescent $C$. musae infections in the immature fruit. $P$. musarum incites minute, scattered spots, referred to as freckles, in the superficial tissues of immature banana peel which do not expand during maturation or ripening. P. musarum does not appear to have a direct suppressive effect on $C$. musae as conidia of $C$. musae germinate on both freckled and non-freckled fruit forming quiescent infections. Our investigations have shown that $P$. musarum infection induced several defence responses in fruit including the accumulation of five phytoalexins, upregulation of chitinase and $\beta-1,3$-glucanase, phenylalanine ammonia lyase (PAL) activity and cell wall lignification. ${ }^{1} \mathrm{H}$ and ${ }^{13} \mathrm{C}$ NMR spectral data of one purified phytoalexin compared closely with 4'-hydroxyanigorufone. Some of the $P$. musarum-induced defences that retained during ripening, restrict $C$. musae development at the ripe stage. This paper examines the potential of $P$. musarum-induced defences, in the control of anthracnose, the most destructive postharvest disease in banana.
\end{abstract}

Keywords : anthracnose, Colletotrichum musae, freckle disease in banana, induced defences, Phyllosticta musarum

Plants have evolved powerful defence mechanisms to counter invading pathogens. Induced defence responses in plants initiate through triggering a cascade of signaling events that lead to generation of reactive oxygen species, hypersensitive response, accumulation of phytoalexins and pathogenesis-related (PR) proteins. The local defence responses often trigger nonspecific resistance throughout the plant, providing durable resistance against challenge infection by a broad range of pathogens. Induced resistance has received increasing attention over the years as a strategy for

\footnotetext{
*Corresponding author.

Phone) +94-81-239-4538, FAX) +94-81-238-8018

E-mail)charmaliea@gmail.com
}

management of postharvest disease in fresh produce (Adikaram, 1990; Terry and Joyce, 2004).

Anthracnose in ripe banana caused by Colletotrichum musae is recognized as the most destructive disease in all banana producing and marketing countries in the world. The disease originates from quiescent infections that take place long before harvest. The basis of resistance of immature bananas to C. musae has been of interest from early days (Simmonds, 1963). Brown and Swinburne (1980) demonstrated by TLC bioassay, the accumulation of at least five phytoalexins in the peel tissue beneath drops of conidia of $C$. musae applied on the surface of green bananas. One of these was later identified as 2-(4'-hydroxyphenyl)-naphthalic anhydride, a phenalenone type phytoalexin (Hirai et al., 1994). One more phenalenone, emenolone, was identified from banana leaves infected with Mycospherella fijiensis (Luis et al., 1993). Fourteen phenyl-phenalenones and their derivatives, including three new compounds were isolated from the peel of unripe M. acuminata (AAA) cv. 'Bungulan' fruit which had been injured and inoculated with C. musae (Kamo et al., 1998). The phenylphenalenone content in unripe and ripe fruit of $M$. acuminata, after wounding and/or inoculation, exposure to ethylene or phenylalanine ammonia lyase (PAL) inhibitors was estimated. Hydroxyanigorufone was induced more in wounded fruits than in inoculated fruits, suggesting that it could be a stress metabolite, and decreased on ripening by exposure of the wounded fruit to ethylene (Kamo et al., 2000). Kamo et al. (2001), while reporting six new phenalenones accumulated in unripe fruit peels of $M$. acuminata upon infection by C. musae, an alternative pathway for biosynthesis of 4phenylphenalenones from 9-phenylphenalenones was also proposed.

Plants, upon pathogen infection or insect attack, induce PR proteins which are considered to be associated with plant defence. They have been classified into 17 families and include $\beta$-1,3-glucanase (PR 2), chitinases (PR 3, 4, 8 $\& 11$ ) and defensins (PR 12) (Ferreira et al., 2007). In banana fruits, chitinase (MaChit gene) had constitutive expression during development and after harvest (Kesari et al., 2010) reaching the highest level during ripening. Infec- 
tion of fruit by $C$. musae increased its expression (Tang et al., 2010).

The control of banana anthracnose has been attempted by many workers (Jeffries et al., 1990), however, the potential of induced defences has been exploited only minimally. Our investigations have revealed that $P$. musarum which causes freckle disease induces several defences in the peel which restrict development of anthracnose disease by C. musae. The freckle of leaf and fruit of bananas and plantains has been recorded in the Asia, Pacific, Americas, and more recently in Australasia-Oceania and South and South East Asia (Liberato et al., 2006). The disease is characterized by minute, isolated pin-head sized spots in the superficial cell layers of the banana fruit peel. Freckles do not expand into progressive lesions during ripening. Freckle disease slightly reduces the cosmetic value of the fruits and sometimes fruit growth. Freckle disease is observed in banana cultivar 'Embul' (Mysore, AAB) a cultivar commonly grown in Sri Lanka which is susceptible to anthracnose. This paper, while reporting the nature of P. musaruminduced defence responses in unripe bananas, cultivar 'Embul', examines their role on the resistance of freckleinfected bananas to anthracnose development by $C$. musae during ripening and the potential use of $P$. musaruminduced defences in the protection of bananas from anthracnose disease.

\section{Materials and Methods}

Fruits. Banana fruits, cultivar 'Embul' (Mysore, AAB), infected with $P$. musarum without any other visible infections and blemishes, harvested 12-13 weeks after bunch emergence from a field maintained in the University of Peradeniya premises were used for all experiments described in this paper unless otherwise stated. Fungicides were not applied at any stage of fruit development. Infected fruits were categorized, based on the number of freckles per $\mathrm{cm}^{2}$ area (FPA), in to 5 categories, 5, 15, 40, 120 and 200 FPA. Healthy fruits, devoid of freckles (0 FPA), were used as control fruits when necessary.

Development of anthracnose in $P$. musarum-infected bananas during ripening. Bananas were brought to the laboratory and separated into three infection categories 0 , 40 and 200 FPA. Two sets, each containing 48 uniformsized fingers from each infection category, were prepared. One set of fruit was stored in boxes at room temperature $\left(26 \pm 2{ }^{\circ} \mathrm{C}\right)$ and allowed to ripen, the size $\left(\mathrm{cm}^{2}\right)$ of anthracnose lesions developed from natural infections was measured daily for 11 days. The second set was inoculated by applying drops $(20 \mu \mathrm{l})$ of $10^{6}$ conidia/ml of C. musae (3 drops per fruit along the long axis). The inoculated fruits were incubated in moisture chambers at room temperature for 7 days and the size $\left(\mathrm{cm}^{2}\right)$ of anthracnose lesions developed was measured and recorded daily. The average lesion size was calculated for each category.

Quiescent $C$. musae infections in the banana peel. A method used to estimate quiescent Alternaria alternata infections in mango (Prusky et al., 1981) was used after minor modifications. Five bananas at harvesting maturity with 0 and 200 FPA were obtained and each fruit was weighed. Four peel segments $\left(0.5 \mathrm{~cm}^{2}, 2 \mathrm{~mm}\right.$ thick $)$ each were cut separately from the blossom-end, stalk-end, inner surface, outer surface and the lateral surface of each fruit. The tissue segments were surface sterilized in $0.1 \%$ sodium hypochlorite for $3 \mathrm{~min}$ and placed on Cook's No. 2 (25\% strength) medium. The plates were incubated for 5 days at room temperature. Presence or absence of $C$. musae growth was recorded for each segment and the percent segments that developed $C$. musae colonies was determined for each category. The percent quiescent infection in a fruit (I) was calculated as $\%$ infected discs in each zone divided by the number of regions. Fruit surface area $(\mathrm{S})$ with quiescent $C$. musae infections was estimated as $\mathrm{S}=\mathrm{I} . \mathrm{W}^{2 / 3}(\mathrm{~W}=$ fruit weight) and transformed into values proportional to its surface area (Prusky et al., 1981). It was assumed that the number of $C$. musae colonies is proportionate to the number of quiescent infections in the peel.

Detection of phytoalexins in the $\boldsymbol{P}$. musarum-infected peel. Peel tissues ( $1 \mathrm{~mm}$ thick) were cut from P. musaruminfected (200 FPA) unripe fruits using a razor blade and control fruit (0 FPA) for all extractions reported in this paper, weighed and frozen $\left(-20^{\circ} \mathrm{C}\right)$. Antifungal compounds were extracted by solvent infiltration under vacuum. Peel tissues $(10 \mathrm{~g})$ were separately placed in ethyl acetate (100 $\mathrm{ml}$ ) in $250 \mathrm{ml}$ conical flasks with side arms that were serially connected to a vacuum pump. The solvent infiltration continued for $1 \mathrm{~h}$ under continuous magnetic stirring. The extract was filtered through Whatman No. 1 filter paper. The residue was placed in another $100 \mathrm{ml}$ portion of fresh ethyl acetate and the vacuum infiltration continued for five times. All extracts were combined and evaporated to dryness under vacuum at $40^{\circ} \mathrm{C}$. The residue was collected in $1 \mathrm{ml}$ ethyl acetate (Adikaram and Bandara, 1998). Aliquots $(50 \mu \mathrm{l})$ were spotted in two Thin Layer Chromatography plates (Silica gel, $\mathrm{GF}_{254}$, Merck) and the plates were developed in chloroform:methanol $(95: 5, \mathrm{v} / \mathrm{v})$ and allowed to airdry overnight. A thick suspension of conidia of Cladosporium cladosporioides, prepared in Czapek Dox nutrient solution, was carefully sprayed onto one plate. The other plate was sprayed with a similarly prepared conidial suspension of $C$. musae. The plates were incubated in a moist chamber at 
room temperature until fungal growth was visible. The presence of inhibitory substances was indicated by the absence of aerial mycelium (Klarman and Stanford, 1968).

Antifungal activity of $P$. musarum infected fruit peel with different degrees of infections and at different ripening stages. Peels ( $1 \mathrm{~mm}$ thick, $10 \mathrm{~g}$ ) were cut from fruits with different freckle infections, FPA 5, 15, 40, 120 and 200 and extracted separately as described previously. Aliquots $(50 \mu \mathrm{l})$ were bioassayed on TLC using C. cladosporioides or $C$. musae. The size of inhibition areas was measured and their Rf values were recorded.

Four replicate sets, each comprising 14 fingers at harvesting maturity with $P$. musarum infections (200 FPA), were allowed to ripen in aluminium trays at room temperature. Two fingers from each set were removed on day 1 and the outer peel tissue ( $1 \mathrm{~mm}$ thick, $10 \mathrm{~g}$ ) was cut and frozen (-20 ${ }^{\circ} \mathrm{C}$ ). Tissues were similarly cut from fruits for 7 consecutive days. At the end of 7 days, the fruits were fully ripe. Tissue samples were extracted and concentrated extracts were bioassayed as described previously. The relative size and the Rf values of inhibition on TLC plates were recorded.

\section{Purification of phytoalexins from $\boldsymbol{P}$. musarum-infected} banana peel. Peel $(1 \mathrm{~mm}$ thick, $200 \mathrm{~g})$ was cut from $P$. musarum-infected bananas (200 FPA) at harvesting maturity, frozen and vacuum infiltrated in ethyl acetate as described previously. The extract was evaporated to dryness. The residue ( $2 \mathrm{~g}$ ) dissolved in ethyl acetate was subjected to bioassay-monitored fractionation by Medium Pressure Liquid Chromatography (MPLC) (Silica gel 60, 0.040-0.063 mm, Merck, $20 \times 2.5 \mathrm{~cm}$ ) with increasing solvent polarity (hexane, dichloromethane, methanol). Fractions having similar TLC behaviour were combined. The nine fractions obtained were bioassayed on TLC using C. cladosporioides or C. musae. Fractions 3 and 4, which displayed antifungal activity, were further purified by a normal phase HPLC column (Partisil $10 \mathrm{M} 9 / 50$ [50 $\mathrm{cm} \times 9.4 \mathrm{~mm}$ i.d], Waters, 2690 separation module, USA), coupled with a RI detector (Waters, Differential refractometer R401), using isocratic elution with ethyl acetate and hexane $(9: 1, \mathrm{v} / \mathrm{v})$ at a flow rate of $1 \mathrm{ml} /$ min. Fraction 6 was chromatographed on a flash column (Silica gel 60,2 $\times 1.5 \mathrm{~cm}$ ) using hexane, dichloromethane and methanol as eluting solvents, and the fraction that eluted with $2 \%$ methanol in dichloromethane afforded red crystals. Fraction 7 was purified by flash column chromatography (Silica gel 60,2 × $1.5 \mathrm{~cm}$ ), eluted with $2 \%$ methanol in dichloromethane and further purified by preparative TLC (Silica gel $60 \mathrm{GF}_{254}$, Merck). ${ }^{1} \mathrm{H}$ NMR (and ${ }^{13} \mathrm{C} \mathrm{NMR}$ ) spectral data of the purified compounds were recorded on a Varian Mercury 300 (300/75 MHz for ${ }^{1} \mathrm{H} /{ }^{13} \mathrm{C}$ NMR) spectrometer in acetone- $\mathrm{d}_{6}$ or DMSO- $\mathrm{d}_{6}$ solution with tetramethyl- silane as an internal reference.

Chitinase and $\beta$-1,3-glucanase activity in $P$. musarum infected fruits and in fruits artificially inoculated with C. musae. Peels ( $1 \mathrm{~mm}$ thick, $1 \mathrm{~g}$ ), from $P$. musarum infected mature, unripe fruits ( 0 and 200 FPA) were cut and subjected to chitinase and $\beta$-1,3-glucanase assays. Chitinase activity was assayed by the method described by Zou et al. (2002) after slight modifications. Tissue sample (1 g) was homogenized in $5 \mathrm{ml}$ of sodium phosphate buffer $(\mathrm{pH} 5)$ for 2 min, using an ultrasonic homogenizer (ULTRA TURRAX ${ }^{\circledR}$ T25 basic, IKA LABORTECHNIK) at 11,000 rpm. The homogenate was clarified by centrifugation at $6000 \mathrm{~g}$ (Sigma 3K30 Laboratory centrifuge) and $4^{\circ} \mathrm{C}$ for $10 \mathrm{~min}$. The supernatant was used for enzyme assay. AgaroseGlycol chitin substrate was prepared (Trudel and Asselin, 1989) and poured in to petri dishes. Aliquots $(10 \mu \mathrm{l})$ of extract or standard chitinase (from Serratia marscescens, Chitinase EC 3.2.1.14, Sigma) were added to wells (2 mm diameter) cut in the gel and the plates were incubated for $20-22 \mathrm{~h}$ at $26^{\circ} \mathrm{C} \pm 2$. The gel plate was stained with $0.1 \%$ (W/V) Calcofluor dye (Fluorescent Brightner 28, Sigma) for $20 \mathrm{~min}$ and washed with SDW for $2 \mathrm{~h}$ in an orbital shaker (IKa-Vibrax-VXR). The hydrolyzed zones were visualized by placing the gel under UV light [Mineralight ${ }^{\circledR}$ Lamp (365 nm), model UV GEL-58; Chromato-VUE Cabinet, model cc-10] and the diameter of the darker hydrolyzed zones was recorded. Sample enzyme activity was determined using a regression equation obtained from chitinase standards.

For $\beta$-1,3-glucanase, peel samples ( $1 \mathrm{~g}$ ) were homogenized at $11,000 \mathrm{rpm}$ in a pre-cooled centrifuge tube with $1 \%(\mathrm{w} / \mathrm{w})$ polyvinyl polypyrrolidone and $5 \mathrm{ml}, 50 \mathrm{mM}$ potassium acetate buffer ( $\mathrm{pH}$ 5), containing $1 \mathrm{mM}$ EDTA and $5 \mathrm{mM}$ reduced glutathione (Dann and Deverall, 2000). Extracts were centrifuged at $9000 \mathrm{~g}$ for $5 \mathrm{~min}$ at $4^{\circ} \mathrm{C}$ and the supernatant was used for enzyme assay. Potassium acetate buffer $(1.6 \mathrm{ml}, 10 \mathrm{mM}, \mathrm{pH} 5)$ and crude extract $(0.4$ $\mathrm{ml})$ were allowed to equilibrate to $30^{\circ} \mathrm{C}$ for $3 \mathrm{~min}$. The reaction was initiated by the addition of $0.4 \mathrm{ml}$ of the substrate (Pachyman) suspension and was stopped after 10 min by addition of $2.8 \mathrm{ml}$ of $20 \%$ (w/v) Tris. The tube was vortexed for $5 \mathrm{~min}$ and centrifuged at $9000 \mathrm{~g}$ for $3 \mathrm{~min}$. Aliquots $(3.0 \mathrm{ml})$ of supernatant were transferred to cuvettes (Optiglass Ltd. England) and the absorbance was measured at $610 \mathrm{~nm}$ against a blank containing substrate but no enzyme extract, using a spectrophotometer (Cam Spec M302) (Dann and Deverall, 2000). Enzyme activity was expressed as absorbance at $610 \mathrm{~nm}$.

Further, a set of 30 P. musarum infected (200 FPA) and another set of 30 healthy fruits (0 FPA) were inoculated with drops $(20 \mu \mathrm{l})$ of $10^{6}$ conidia/ml of $C$. musae (3 drops 
per fruit). Another set of fruits was treated with drops of SDW as controls. All fruits were kept in moist chambers at room temperature. Peels ( $1 \mathrm{~mm}$ thick, $1 \mathrm{~g})$, cut from the inoculation sites from each treatment at $0,2,4,6$ and 8 days after inoculation, were frozen $\left(-17^{\circ} \mathrm{C}\right)$ and extracted for chitinase and $\beta$-1,3-glucanase as above. Inoculated fruits were observed daily for anthracnose and the lesion area was measured.

Phenylalanine ammonia lyase (PAL) activity and lignification in the $\boldsymbol{P}$. musarum-infected peel. Peel tissue obtained from healthy and P. musarum-infected (200 FPA), young ( 2 weeks) and mature (12-13 weeks after flowering) bananas were separately homogenized in cold acetone $\left(-18^{\circ} \mathrm{C}\right)$. PAL was extracted from $0.4 \mathrm{~g}$ of the acetone powder with $15 \mathrm{ml}$ of $0.1 \mathrm{M}$ sodium borate buffer $(\mathrm{pH} 8.8)$ containing $20 \mathrm{mM} \beta$-mercaptoethanol. The enzyme activity was assayed by following the production of cinnamic acid after incubation at $40^{\circ} \mathrm{C}$ for $2 \mathrm{~h}$, at $290 \mathrm{~nm}$ with the use of a spectrophotometer (Cam-Spec M302-UV visible, WPA Ltd. UK) (Martinez-Tellez and Lafuente, 1993). Cinnamic acid concentration (in ppm) was determined using a standard curve, cinnamic acid concentration vs absorbance $(290 \mathrm{~nm})$. Four replicate samples were used.

In order to observe lignified cells, thin, transverse, sections were cut through healthy (0 FPA) or P. musarum-infected (200 FPA) peel using a razer blade and placed in a drop of $1 \%$ phloroglucinol on a slide. After placing a coverslip, a drop of $25 \%$ of $\mathrm{HCl}$ was allowed to diffuse in through the edge of the cover slip and colour changes were recorded (Johansen, 1940).

The cell wall bound phenolic acids were extracted by homogenizing $P$. musarum infected (200 FPA) or healthy peel (0 FPA) tissues ( $1 \mathrm{~g})$ in liquid nitrogen, using a homogenizer (ULTRA TURRAX ${ }^{\circledR}$, T25 basic, IKA Labortechnik, Australia) for $1 \mathrm{~min}$ at $11,000 \mathrm{rpm}$ with $5 \mathrm{ml}$ of $80 \%$ $\mathrm{MeOH}$. The extract was centrifuged (M.S.E. England) at $10,000 \mathrm{~g}$ for $10 \mathrm{~min}$ and the resulting precipitate was dried at $70^{\circ} \mathrm{C}$ for $24 \mathrm{~h}$ in an oven (Hotbox, Gallenkamp Ltd., UK), re-suspended in $0.5 \mathrm{M} \mathrm{NaOH}$ for $1 \mathrm{~h}$ at $96^{\circ} \mathrm{C}$ and centrifuged at $10,000 \mathrm{~g}$ for $10 \mathrm{~min}$. The supernatant was acidified (with Conc. $\mathrm{HCl}$ ) and mixed with anhydrous diethyl ether, and separated using a separation funnel. The ether extract was reduced to dryness under vacuum at $40^{\circ} \mathrm{C}$, and the precipitate was re-suspended in $0.25 \mathrm{ml}$ of $50 \%$ $\mathrm{MeOH}$ (De Ascensao and Dubery, 2003). The phenolic content was measured using the Folin-Ciocalteau assay.

Statistical analysis. All experiments described above were repeated three times. The data were analyzed by ANOVA using General Linear Model (GLM) procedure. Means were separated by Duncan's Multiple Range Test (DMRT) using SAS computer software (Release 6.12), other than for the analysis of cell wall bound phenolics, where t-test was used (MINITAB statistical software, Release 13.1). The differences at $5 \%$ level were considered as significant.

\section{Results}

Freckle infection of bananas. Freckle symptoms caused by P. musarum (Teleomorph Guignardia musae) appear as soon as the banana bunch has shot, initially as minute, greybrown, circular spots of about $0.25 \mathrm{~mm}$ diameter with a water soaked halo of about $1.5 \mathrm{~mm}$ diameter around each spot. A typical freckle in mature fruits is rough to the touch, and heavy infections may give a reddish-brown colour to the fruit. The fungus produces pycnidia embedded in the sub-epidermal tissue of the banana peel (Fig. 1). In addition perithecia with oval, single celled ascospores of the teleomorph $G$. musae were occasionally observed.

Development of anthracnose lesions in $P$. musaruminfected bananas. Healthy fruits developed anthracnose lesions from natural $C$. musae infections much earlier than P. musarum-infected fruits. The total area covered by anthracnose lesions in non-freckled fruits was significantly $(p<0.05)$ larger than that of $P$. musarum-infected ones. The heavily $P$. musarum-infected (FPA 200) bananas had much smaller areas of anthracnose than the moderately P. musaruminfected (FPA 40) fruits. A similar trend was observed in the $P$. musarum-infected fruits that were artificially inoculated with $C$. musae (Table 1 and Fig. 2) where anthracnose lesions appeared several days earlier than fruits that had only natural $C$. musae infections. Fruits without $P$. musarum infections showed first symptoms of anthracnose 5 days after inoculation which expanded into larger lesions within another two days. The heavily $P$. musarum-infected fruits did not show symptoms until the $7^{\text {th }}$ day. The moderately infected fruits had slightly brownish lesions on the $7^{\text {th }}$ day which were much smaller in size than those in the fruits

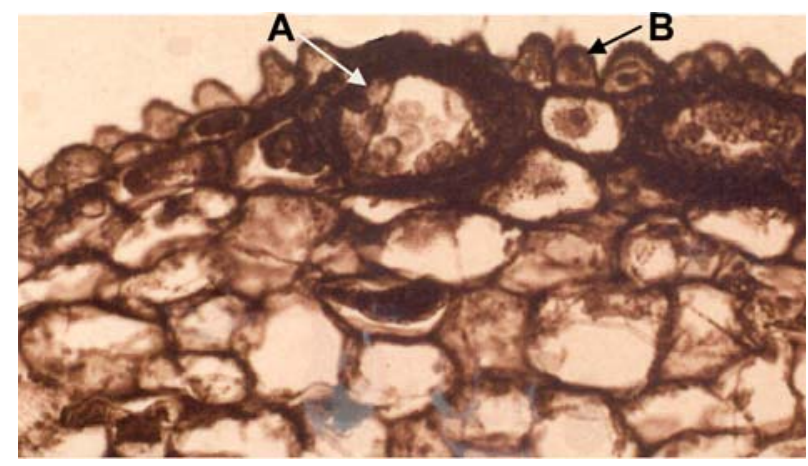

Fig. 1. Transverse section of freckle-infected peel showing pycnidia of Phyllosticta musarum $(4 \times 10)$. A: pycnidia, B: epidermis. 
Table 1. Anthracnose development during ripening in healthy and P. musarum-infected bananas cv. 'Embul' following inoculation or natural infection with $C$. musae. Each data point represents the mean lesion area of 48 fruits per day (experiment was repeated 3 times)

\begin{tabular}{cccc}
\hline \hline & \multicolumn{3}{c}{ Average lesion area per fruit $\left(\mathrm{cm}^{2}\right)$ at FPA } \\
\cline { 2 - 4 } & 0 & 40 & 200 \\
\hline $\begin{array}{c}\text { 7 days after } \\
\text { inoculation (AI) }\end{array}$ & $4.94^{\mathrm{a}} \pm 1.06$ & $0.79^{\mathrm{b}} \pm 0.04$ & $0.03^{\mathrm{b}} \pm 0.01$ \\
days after harvest (NI) & & & \\
9 & $0.93^{\mathrm{a}} \pm 0.06$ & $0.44^{\mathrm{b}} \pm 0.03$ & $0.21^{\mathrm{b}} \pm 0.04$ \\
10 & $2.73^{\mathrm{a}} \pm 0.29$ & $0.64^{\mathrm{b}} \pm 0.02$ & $0.51^{\mathrm{b}} \pm 0.06$ \\
11 & $4.51^{\mathrm{a}} \pm 0.56$ & $2.36^{\mathrm{b}} \pm 0.15$ & $0.84^{\mathrm{b}} \pm 0.09$ \\
\hline
\end{tabular}

FPA - Freckles per $\mathrm{cm}^{2}$ area. $\mathrm{NI}=$ natural infections, $\mathrm{AI}=$ artificial inoculation

Means ( \pm standard deviation) in a row followed by the same letters are not significantly different according to DMRT $(p<0.05)$.

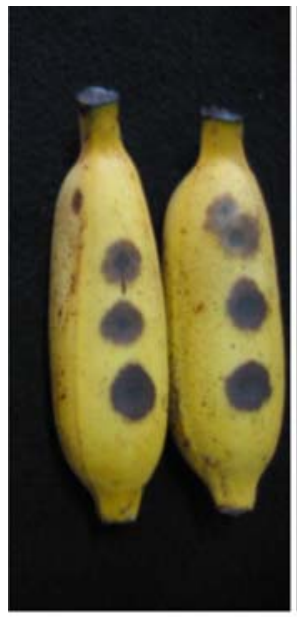

A

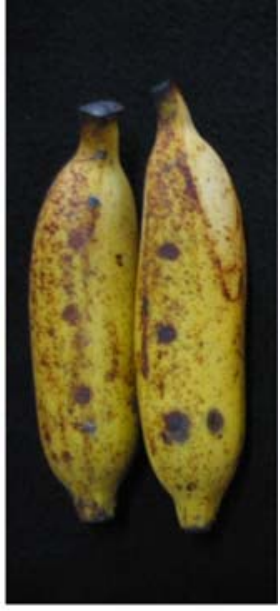

B
Fig. 2. Anthracnose development in artificially inoculated fruits with $C$. musae five days after inoculation in (A) healthy banana, (B) P. musarum infected banana (40 FPA).

devoid of P. musarum infections.

Extent of quiescent $\boldsymbol{C}$. musae infections in the banana peel. Percentage peel segments that produced $C$. musae colonies was taken as an indication of the degree of quiescent C. musae infections in the fruit peel. The peel segments removed from $P$. musarum-infected banana produced a significantly $(p<0.05)$ greater number of $C$. musae colonies than those of controls indicating the presence of more quiescent propagules of $C$. musae in the P. musaruminfected peel (Table 2).

Phytoalexins in $\boldsymbol{P}$. musarum-infected banana peel. Thin layer chromatograms of ethyl acetate extracts of the $P$.
Table 2. Percentage (I) and surface area (S) with $C$. musae quiescent infections in healthy and $P$. musarum-infected fruit peel segments, after incubation for 5 days at room temperature on Cook's No. 2 ( $25 \%$ strength) medium. Each data point represents the mean values of I or S from 20 peel segments (experiment was repeated 3 times)

\begin{tabular}{lcc}
\hline \hline & $0 \mathrm{FPA}$ & $200 \mathrm{FPA}$ \\
\hline \% quiescent $C$. musae infections (I) & $4.33^{\mathrm{a}} \pm 0.51$ & $13.66^{\mathrm{b}} \pm 0.99$ \\
quiescent $C$. musae infected fruit & $46.89^{\mathrm{a}} \pm 1.23$ & $159.35^{\mathrm{b}} \pm 5.27$ \\
surface (S) & & \\
\hline
\end{tabular}

$\mathrm{FPA}=$ freckles per $\mathrm{cm}^{2}$ area

$\mathrm{S}=\mathrm{I} . \mathrm{W}^{2 / 3}, \mathrm{I}=\%$ infected discs in each zone divided by the number of regions. $\mathrm{W}=$ fruit weight (Prusky et al., 1981).

Means ( \pm standard deviation) in a row followed by the same letters are not significantly different according to DMRT $(p<0.05)$.

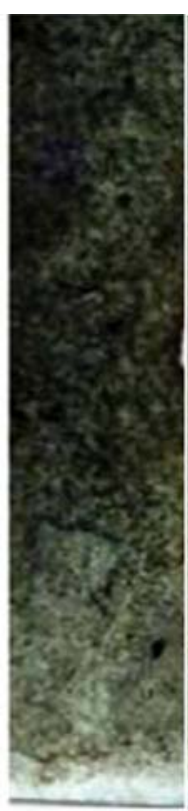

A

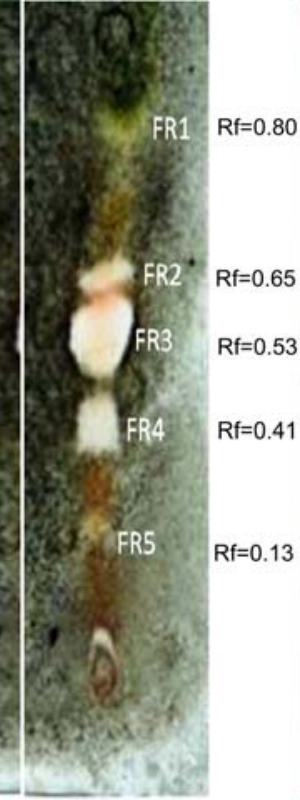

B

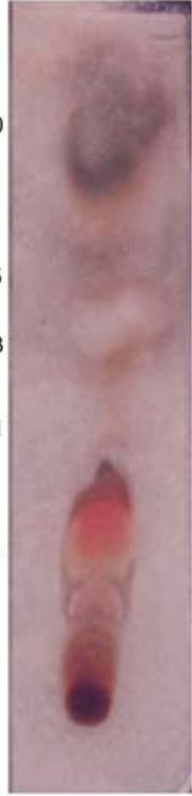

C

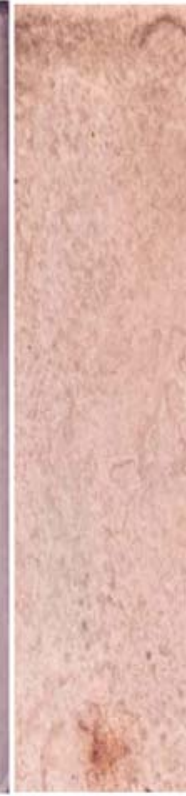

D
Fig. 3. TLC bioassay of ethyl acetate extracts of peel of (A) healthy and (B) P. musarum-infected fruit peel showing zones of inhibition using C. cladosporioides. (C) P. musarum-infected and (D) healthy fruit peel showing zones of inhibition using C. musae.

musarum-infected peel, over sprayed with $C$. cladosporioides or $C$. musae, showed five antifungal zones, including a large zone at Rf 0.53 (FR3). There were two smaller but prominent inhibitory zones at Rf 0.41 (FR4) and 0.65 (FR2) and other two less prominent antifungal zones, FR1 and FR5 (Fig. 3b). There was no difference in the number and size of inhibitory zones between the TLC plates bioassayed with $C$. cladosporioides and C. musae (Fig. $3 \mathrm{~b}$ and 3c). Antifungal activity was not detected in the extracts of healthy fruit peel. The antifungal profile of 5 other local banana cultivars infected with P. musarum was more or less similar to that of cultivar 'Embul' (data not provided). $C$. 


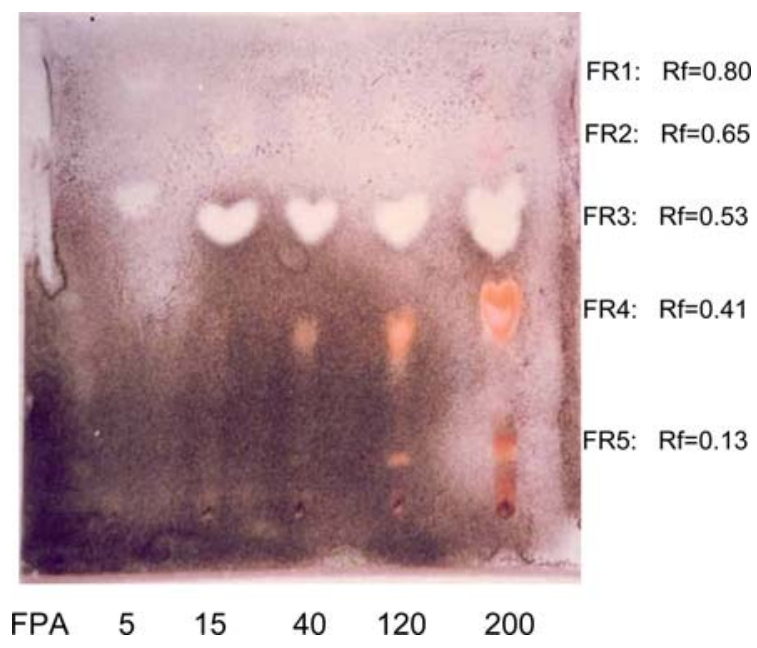

Fig. 4. TLC bioassay (using C. cladosporioides) of ethyl acetate extracts of $P$. musarum infected fruit peel having different freckle intensities.

musae infected peel extracts showed traces of antifungal activity on TLC plates (data not provided).

Antifungal activity of fruit peel with different degree of P. musarum infections. Thin layer chromatograms with extracts of the peel containing different degrees of freckle infections, oversprayed with $C$. cladosporioides showed three to five antifungal zones, which increased in number and size with the increase in freckling (Fig. 4). The size of the inhibition zone at Rf 0.53 (FR3) produced by extract taken from the heavily P. musarum-infected peel was larger than that of the extract taken from moderately P. musaruminfected peel. An inhibition zone at Rf 0.41 (FR4) appeared when infection exceeded $40 \mathrm{FPA}$ and the size of this inhibition zone increased with the increase in the degree of P. musarum infection. The same pattern was observed with the inhibition zone at $\mathrm{Rf} 0.13$ (FR5). The chromatogram sprayed with conidia of $C$. musae consisted of a similar antifungal profile.

Antifungal activity of the $P$. musarum-infected peel at different stages of ripening. The extracts of peel tissue taken from P. musarum-infected fruits (40 and 200 FPA), one day after harvest produced a prominent inhibition area at Rf 0.6 (FR2). The size of the inhibition area at $\mathrm{Rf} 0.53$ (FR3) which was also large in the extracts obtained from fruits at day zero, but decreased progressively during fruit ripening. Most of the activity at Rf. 0.53 (FR3), however, remained during ripening. The peels taken from fully ripened fruits still showed considerable antifungal activity.

Purification of phytoalexins. TLC bioassay of nine MPLC fractions using C. cladosporioides showed antifungal activity

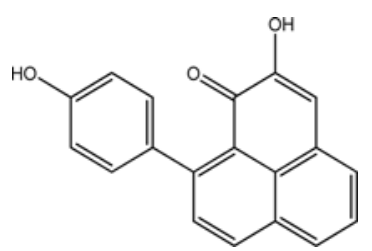

Fig. 5. Structure of 4'-hydroxyanigorufone (C7).

in the fractions 3, 4, 6, and 7. Fraction 3 was further purified by a normal phase HPLC column, and this gave a colourless oil (10 mg, C3 - from inhibition zone FR2 in Fig. 3b). Purification of fraction 4 yielded a colourless compound ( 5 mg, C4 - from inhibition zone FR3 in Fig. 3b). The fraction 6 gave red needle-shaped crystals $(25 \mathrm{mg}, \mathrm{C} 6$ - from inhibition zone FR4 in Fig. 3b) which were identified as irenolone, by comparing ${ }^{1} \mathrm{H} /{ }^{13} \mathrm{C}$ NMR spectral data with those previously reported by Luis et al. (1993); ${ }^{1} \mathrm{H}$ NMR (in acetone- $\mathrm{d}_{6}$ ) chemical shifts appeared at $\delta 8.57(\mathrm{dd}), 8.30$ (dd), 7.95(d), 7.76(dd), 7.50(d), 7.26(d), 7.10(s) and 6.91(d), and ${ }^{13} \mathrm{C}$ NMR (in acetone- $\mathrm{d}_{6}$ ) appeared at $\delta 180,157.5$, $151.5,144,136,132,131,130,129.9,127,126,116$ and 112. Purification of fraction 7 , resulted in a red colour active compound (15 mg, C7- from inhibition zone FR4 in Fig. 3b), which was identified as 4'-hydroxyanigorufone (Fig. 5) by comparing ${ }^{1} \mathrm{H}$ NMR spectral data with literature values (Luis et al., 1996); ${ }^{1} \mathrm{H}$ NMR (in DMSO-d $\mathrm{d}_{6}$ ) chemical shifts appeared at $\delta 9.55$ (broad s), 9.25 (broad s), 8.32 (d), 8.01 (dd), 7.80 (d), 7.62 (dd), 7.57 (d), 7.20 (d), 7.10 (s) and $6.81(\mathrm{~d})$.

Chitinase and $\beta-1,3$-glucanase activity in $P$. musarum infected fruits. Detectable chitinase and $\beta$-1,3-glucanase activity in the extract of the $P$. musarum infected peel tissue (FPA 200) was significantly higher, when compared to the healthy fruit peel. In addition the activity of both enzymes increased with the increase in freckle intensity (Table 3). During ripening, an upregulated chitinase activity was observed in the P. musarum infected, as well as the healthy peel tissue. This increase was significantly higher in the $P$.

Table 3. Chitinase and $\beta$-1,3-glucanase activity of mature, unripe banana fruit peel with varying intensities of $P$. musarum infection. Each data point represents the mean values of three replicate bunches

\begin{tabular}{ccc}
\hline \hline $\begin{array}{c}\text { Freckle infection } \\
\text { (FPA) }\end{array}$ & $\begin{array}{c}\text { Chitinase activity } \\
\text { (Units/g FW) }\end{array}$ & $\begin{array}{c}\text { *Relative } \beta \text {-1,3-gluca- } \\
\text { nase activity }\end{array}$ \\
\hline 0 & $0.47^{\mathrm{a}} \pm 0.47$ & $0.140^{\mathrm{a}} \pm 0.01$ \\
40 & $2.07^{\mathrm{a}} \pm 1.01$ & $0.244^{\mathrm{b}} \pm 0.01$ \\
200 & $33.93^{\mathrm{b}} \pm 9.72$ & $0.450^{\mathrm{c}} \pm 0.03$ \\
\hline
\end{tabular}

$\mathrm{FPA}=$ freckles per $\mathrm{cm}^{2}$ area $*$ Absorbance at $610 \mathrm{~nm}$

Means ( \pm standard deviation) in a column followed by the same letters are not significantly different according to DMRT $(p<0.05)$. 

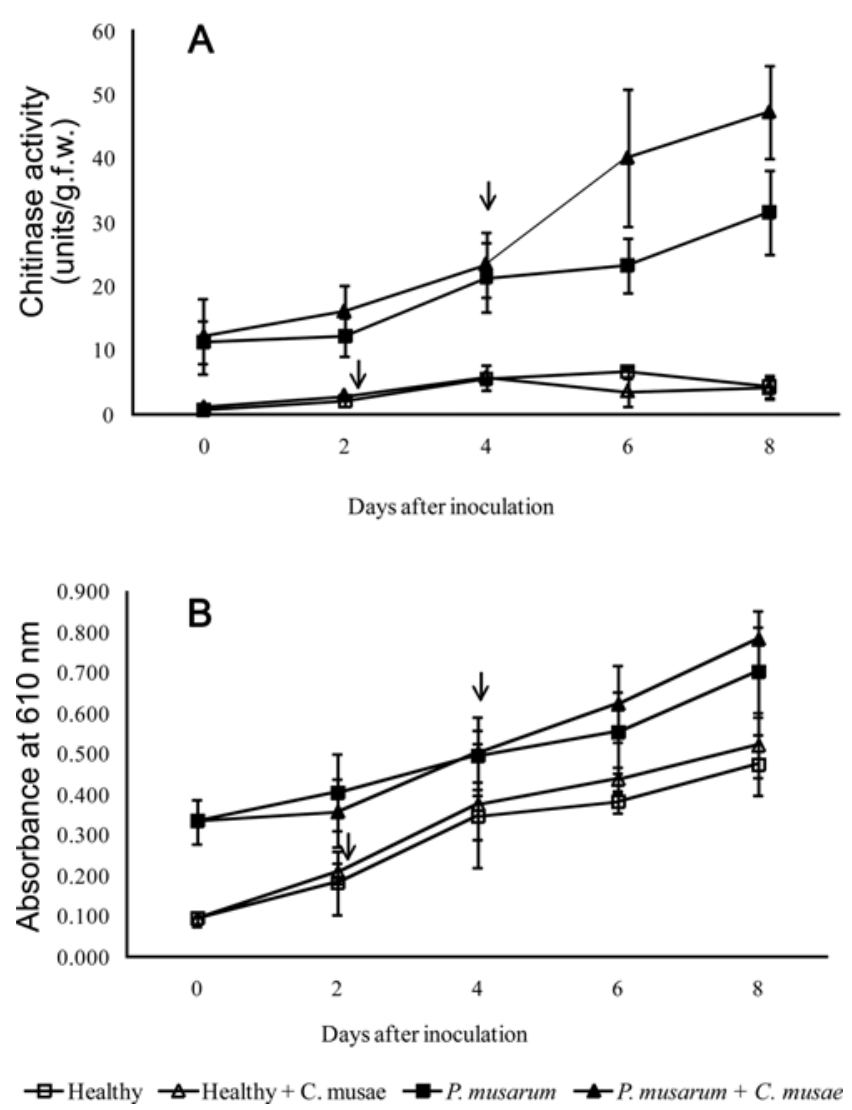

Fig. 6. (A) Chitinase and (B) $\beta-1,3$-glucanase activity in the peel of $P$. musarum infected or healthy fruits challenge inoculated with or without $C$. musae during ripening. Each data point represents the mean value of enzymatic activity of peel tissue of 3 fruits per day (experiment was repeated 3 times). Vertical bars represent the standard error. $\downarrow$-Commencement of anthracnose development.

musarum infected peel when compared to the healthy peel. Inoculation with $C$. musae enhanced chitinase activity in the $P$. musarum-infected tissue and in the healthy tissue, while it was significantly higher in the P. musarum infected peel (Fig. 6a). Similarly, when considering, $\beta$-1,3-glucanase activity $P$. musarum-infected peel showed a higher activity when compared to the healthy peel tissue. However, with C. musae inoculation, the increase in $\beta-1,3$-glucanase activity with ripening was not significantly different in the healthy peel when compared to the P. musarum infected peel tissue (Fig. 6b).

PAL activity and lignification. PAL activity was significantly $(p<0.05)$ and $2-3$ times greater in the extract of the P. musarum-infected tissue than in healthy tissue (Table 4). PAL activity was greater in the extracts of the mature $P$. musarum-infected fruit peel compared to those of young fruit peel. Three to four cell layers adjacent to the pycnidia in the $P$. musarum-infected tissue turned red-violet colour
Table 4. Concentration of cinnamic acid produced by PAL activity and cell wall bound phenolics in P. musarum-infected and healthy banana peel tissue. Each data point represents the mean values of three replicate bunches

\begin{tabular}{lcc}
\hline \hline & $\begin{array}{c}\text { Concentration } \\
\text { of cinnamic } \\
\text { acid }\end{array}$ & $\begin{array}{c}\text { Concentration of cell wall } \\
\text { bound phenolic acid } \\
\text { (quantified in ferulic acid } \\
\text { equivalents) }\end{array}$ \\
\cline { 2 - 3 } & $\mathrm{mmol} / \mathrm{gFw} / \mathrm{h}$ & $\mu \mathrm{g} / \mathrm{gFw}$ \\
\hline Young infected peel & $25.3^{\mathrm{a}} \pm 1.02$ & $\mathrm{NA}$ \\
Mature healthy peel & $29.5^{\mathrm{b}} \pm 2.04$ & $\mathrm{NA}$ \\
Mature infected peel & $70.5^{\mathrm{c}} \pm 2.24$ & $0.60^{\mathrm{x}} \pm 0.04$ \\
\hline
\end{tabular}

NA: Not assessed.

Means ( \pm standard deviation) in a column followed by the same letters are not significantly different according to DMRT (concentration of cinnamic acid) and $t$-test (concentration of cell wall bound phenolics) $(p<0.05)$.

showing the presence of lignin. Up to 6-10 epidermal cells bordering the pycnidium were also stained red-violet colour. The healthy tissue did not contain any stained cells in the epidermis or the cell layers below the epidermis. Cell wall bound phenolic acid content was significantly $(p<0.05)$ higher in P. musarum-infected peel when compared to the healthy peel (Table 4).

\section{Discussion}

Anthracnose development by $C$. musae was significantly less in $P$. musarum-infected bananas compared to nonfreckled fruit. With the increase in P. musarum infection, the anthracnose development was observed to decrease further. Conidia of $C$. musae appear to germinate on the surface of banana fruits, with or without $P$. musarum infection, form appressoria prior to becoming quiescent. Further, in most of the attempts made to isolate P. musarum using banana peel tissues and different agar media, growth of $C$. musae occurred instead of $P$. musarum. These may possibly rule out any direct suppressive effect of $P$. musarum on $C$. musae.

P. musarum-infection induces strong antifungal activity in the banana fruit peel consisting of at least five phytoalexins. These are equally toxic to both $C$. cladosporioides and C. musae when used as test organisms. When C. cladosporioides is used as a standard test organism in a TLC bioassay, antifungal zones are clear and visible in contrast to the dark green growth of C. cladosporioides (Klarman and Stanford, 1968). The compound C7, isolated from $P$. musarum-infected peel, has a phenylphenalenone group, and closely compared with 4'-hydroxyanigorufone. The current study revealed that 4'-hydroxyanigorufone exhibits 
antifungal activity, accumulates in the $P$. musarum infected fruit and decreased with ripening. Kamo et al. (2000) found that the level of hydroxyanigorufone in ripe fruit following wounding and/or by inoculation was much lower than that in unripe fruit, indicating that the ripe fruit did not retain the ability to produce most phenylphenalenones. Banana phytoalexins are mainly of the phenanolone type (Luis et al., 1995; Luis et al., 1996) while a phenolic hydroxyl group is essential for their antifungal activity (Kamo et al., 1998). A substitution on the unsaturated carbonyl system or addition of a phenyl group reduces antifungal activity in phenylphenalenones (Quinones et al., 2000). Irenolone was also identified during the current study, a stress metabolite, which did not show antifungal activity.

The level and the number of antifungal compounds in the fruit peel appear to increase with the increase in the degree of $P$. musarum-infection. At least one of these active antifungal zones (C3-colourless oil) is produced in the young $P$. musarum-infected fruit and remained until maturity. However, in the current study a colourless compound (C4) which was produced in the unripe fruit and active, remained through fruit ripening. This may be a compound which inhibits the colonization of $C$. musae, even when the fruits are ripe, offering a continued resistance.

Accumulation of PR proteins is an important feature of plant defense responses upon infection by pathogens (Ferreira et al., 2007). There are two apparent roles that the PR proteins can play in disease resistance. The first is to directly block the development of fungal and bacterial pathogens via hydrolytic action on pathogen cell walls or by other antimicrobial activity (Van Loon, 1997). Apart from the direct breakdown of pathogens, PR proteins can operate in a distinct pathway involving the hydrolytic release of chitin and glucans fragments from fungal cell walls. These oligosaccharides can act as elicitors and induce a chain of defense reactions in the host plant. Constitutive $\beta$-1,3-glucanase has been detected in ripe bananas (Peumans et al., 2000). The current study has shown significantly higher chitinase and $\beta$-1,3-glucanase activity in the $P$. musarum infected peel compared to the healthy peel, indicating a significant increase in the constitutive levels with infection and fruit ripening. It was also observed that chitinase activity was significantly enhanced with $C$. musae lesion development in freckled peels. Similarly, Tang et al. (2010) record that the chitinase gene (MaChit) had constitutive expression in bananas during development and after harvest. MaChit expression increased with time after harvest and reached the highest level at the onset of ripening. They also report that infection of the banana pathogen $C$. musae increased MaChit expression. There is compelling evidence that identical or closely related proteins are also either constitutively expressed in healthy, unstressed plants or as part of a developmental programme
(Leone et al., 2006). A similar situation was observed by Yue-Ming (1997) during a study of anthracnose disease in two banana varieties, where the activity of chitinase and $\beta$ 1,3-glucanase increased gradually during pathogenesis.

Phyllosticta musarum infection in bananas, at both young and mature stages, is also associated with increased PAL activity. PAL, the enzyme which catalyses the conversion of phenylalanine to cinnamic acid, occupies a key position in the biosynthesis of phenylpropanoid phytoalexins. Some of the phytoalexins from the P. musarum-infected tissue may be derived from the shikimic acid pathway leading to phenylpropanoid metabolism, since the phenylphenalanones consist of aromatic phenol rings. PAL activity increased after wounding and ethylene treatment and inhibition of PAL by 2-aminooxyacetic acid inhibits the accumulation of hydroxyanigorufone, indicating that cinnamic acid is a precursor of hydroxyanigorufone (Kamo et al., 2000). Phenylphenalenones are formed via a phenylpropanoid pathway, as observed in plants belonging to the family Musaceae and Haemodoraceae. Lewis and Yamamoto (1990) state that the increase in cell wall bound phenolics may increase esterification and lignification in host cell walls and there by resist the action of lytic enzymes produced by fungal pathogens. The current study revealed increased levels of cell wall bound phenolics and lignins in the P. musarum infected peel tissue.

With the increase of intensity of freckle disease, the accumulation of phytoalexins increased and the resistance to anthracnose increased. Fruits, both with natural $C$. musae infections and artificial inoculations developed anthracnose lesions at a much later stage in the P. musarum-infected fruits than in the healthy ones. Similarly, a correlation between the concentration of phenylphenalenones and the resistance against Mycosphaerella. fijiensis and Fusarium oxysporum in Musa acuminata var. "Gross Michel" (AAA), "Cavendish" (AAA) and "Dominico" (AAB) has been shown (Otalvaro et al., 2002).

Colletotrichum musae produces two types of appressoria on the banana fruit surface, dark and hyaline (Muirhead and Deverall, 1981). The hyaline appressoria which penetrate the unripe fruit peel at an early stage were thought to be provoking defence responses. The dark appressoria on the other hand remain on the surface and become active with fruit ripening to develop anthracnose lesions. C. musae could be isolated more frequently from the $P$. musaruminfected banana peels than from the healthy ones. This may indicate that there are greater numbers of dark appressoria in $P$. musarum-infected peels. It is possible that in the $P$. musarum-infected fruits the dark appressoria are prevented from germinating and the production of many hyaline appressoria is not required due to the defence responses that have already been initiated by the P. musarum infection. 
Current experiments have shown that $P$. musarum is an effective elicitor of defenses in banana. The development of an elicitor substance or a mild strain of the freckle fungus capable of inducing resistance without cellular damage and devoid of freckle symptoms, could have a great practical value in protecting bananas from antracnose. Non-pathogenic or less aggressive microorganisms and mild strains of pathogens, physical and chemical agents have been used to induce resistance in fruits and vegetables against postharvest pathogens. Induction of phytoalexins by Glomerella cingulata infections or treatment with elicitor could successfully protect the Capsicum annum fruits from Botrytis cinerea infections (Adikaram et al., 1988). Biocontrol activity and induced resistance have been a possible modes of action for Aureobasidium pullulans against grey mould of strawberry fruit (Adikaram et al., 2002). These investigations have shown that the induced resistance holds promise as a new technology for the control of postharvest diseases. Such an approach has not hither to been made for bananas.

In this study a number of cellular, chemical and biochemical defense responses in banana fruits due to freckle infections have been revealed, introducing induced resistance as a possible means of controlling anthracnose of bananas. The understanding of the defense mechanisms and their elicitation in fruits could lead to the development of new biological/biotechnological approaches to reduce fungal decay. These could serve as environmentally friendly alternatives to toxic fungicides which are currently used for the control of postharvest disease.

\section{Acknowledgements}

We thank Drs. S. Ratnayake and B.M. Mallika Kumarihamy, formerly of the Department of Chemistry, University of Peradeniya, for their assistance in chemical analysis and the Sri Lanka Council for Agricultural Research Policy and Australian Centre for International Agricultural Research for financial assistance.

\section{References}

Adikaram, N. K. B., Brown, A. E. and Swinburne, T. R. 1988. Phytoalexin induction as a factor in the protection of Capsicum annuиm L. fruits against infection by Botrytis cinerea. Pers. J. Phytopathol 122:267-273.

Adikaram, N. K. B. 1990. Possibility of control of postharvest fungal disease by manipulation of host defence system. Proceedings of the 3rd International Conference on Plant Protection in the Tropics, Genting Highlands, Pahang, Malaysia, 2023 March 1990. (V), 31-36.

Adikaram, N. K. B., Joyce, D. C. and Terry, L. A. 2002. Biocontrol activity and induced resistance as a possible mode of action for Aureobasidium pullulans against grey mould of strawberry fruit. Austral. Plant Pathol. 31:223-229.

Adikaram, N. K. B. and Bandara, B. M. R. 1998. Methodology for studying defense mechanisms against fungal pathogensAn Overview. In: Disease resistance in fruits (Eds) G.I. Johnson, E. Highley, and D. C. Joyce, ACIAR Proceedings No. 80, 177-185.

Brown, A. E. and Swinburne, T. R. 1980. The resistance of immature banana fruits to anthracnose [Colletotrichum musae (Berk. \& Curt.)Arx.]. J. Phytopathol. 99: 70-80.

Dann, E. K. and Deverall, B. J. 2000. Activation of systemic acquired resistance in pea by an avirulent bacterium or a benzothiadiazole, but not by a fungal leaf spot pathogen. Plant Pathol. 49:324-332.

De Ascensao, A. R. D. C. F. and Dubery, I. A. 2003. Soluble and wall-bound phenolics and phenolic polymers in Musa acuminata roots exposed to elicitors from Fusarium oxysporum f.sp. cubense. Phytochemistry 63:679-686.

Ferreira, R. B., Monteiro, S., Freitas, R., Santos, C. N., Chen, Z., Batista, L. M., Duarte, J., Borges, A. and Teixeira, A. R. 2007. The role of plant defense proteins in fungal pathogenesis. Mol. Plant. Pathol. 8:677-700.

Hirai, N., Ishida, H. and Koshimizu, K. 1994. A phenalenonetype phytoalexin from Musa acuminata. Phytochemistry 37:383-385.

Jeffries, P., Dodd, J. C., Jeger, M. J. and Plumbley, R. A. 1990. The biology and control of Colletotrichum species on tropical fruit crops. Plant Pathol. 39:344-366.

Johansen, D. A. 1940. Plant microtechnique. McGraw-Hill, New York.

Kamo, T., Kato, N., Hirai, N., Tsuda, M., Fujioka, D. and Ohigashi, H. 1998. Phenylphenalenone-type phytoalexins from unripe Bungulan banana fruit. Biosci. Biotech. Bioch. 62:95101.

Kamo, T., Hirai, N., Tsuda, M., Fujioka, D. and Ohigashi, H. 2000. Changes in the content and biosynthesis of phytoalexins in banana fruit. Biosci. Biotech. Bioch. 64:2089-2098.

Kamo, T., Hirai, N., Iwami, K., Fujioka, D. and Ohigashi, H. 2001. New phenylphenalenones from banana fruit. Tetrahedron 57:7649-7656.

Kesari, R., Trivedi, P. K. and Nath, P. 2010. Gene expression of pathogenesis-related protein during banana ripening and after treatment with 1-MCP. Postharvest Biol. Tec. 56:64-70.

Klarman, W. L. and Stanford, J. L. 1968. Isolation and purification of an antifungal principle from infected soya beans. Life Sci. 7:1095-1103.

Leone, P., Menu-Bouaouiche, L., Peumans, W. J., Payan, F., Barre, A., Roussel, A., Van Damme, E. J. M. and Rougé, P. 2006. Resolution of the structure of the allergenic and antifungal banana fruit thaumatin-like protein at 1.7-Å. Biochimie 88: 45-52.

Lewis, N. G. and Yamamoto, E. 1990. Lignin: occurrence, biogenesis and biodegradation. Annu. Rev. Plant Physiol. Plant Mol. Biol. 41:455-496.

Liberato, J. R., Van Brunschot, S., Grice, K., Henderson, J., Shivas, R. G. 2006. Banana freckle (Guignardia musae) Pest and 
Diseases Image Library. Department of Primary Industries and Fisheries, Queensland, Australia. http://www.padil.gov.au

Luis, J. G., Echeverri, F., Quinones, W., Brito, I., Lopez, M., Torres, F., Cardona, G., Aguiar, Z., Pelaez, C. and Rojas, M. 1993. Irenolone and Emenolone: Two new types of phytoalexin from Musa paradisiaca. J. Org. Chem. 58:4306-4308.

Luis, J. G., Flecther, Q. W., Echeverri, F., Abad, T., Kishi, P. M. and Perales, A. 1995. New phenalenone-type phytoalexins from Musa acuminata (COLLA AAA) Grand nain. Nat. Product Lett. 6:23-30.

Luis, J. G., Quinones, W., Echeverri, F., Grillo, T. A., Kishi, M. P., Garcia-Garcia, F., Torres, F. and Cardona, G. 1996. Musanolones: four 9-phenylphenalenones from rhizomes of Musa acuminata. Phytochemistry 41:753-757.

Martinez-Tellez, and M. A. and Lafuente, M. T. 1993. Chillinginduced changes in phenylalanine ammonia-lyase, peroxidase, and polyphenol oxidase activities in citrus flavedo tissue. Acta Hort. 343:257-263.

Muirhead, I. F. and Deverall, B. J. 1981. Role of appressoria in latent infection of banana fruits by Colletotrichum musae. Physiol. Plant Pathol. 19:77-84.

Otalvaro, F., Echeverri, F., Quinones, W., Torres, F. and Schneider, B. 2002. Correlation between phenylphenalenone phytoalexins and phytopathological properties in Musa and the role of a dihydrophenylephenalene. Triol. Molecules 7:331-340.

Peumans, W. J., Barre, A., Derycke, V., Rouge, P., Zhang, W., May, D. G., Delcour, J. A., Leuven, F. V. and Van Damme, E. J. M. 2000. Purification, characterization and structural analysis of an abundant $\beta$-1,3-glucanase from banana fruit. Eur. $J$. Biochem. 267:1188-1195.
Prusky, D., Fuchs, Y. and Zauberman, G. A. 1981. A method for preharvest assessment of latent infections in fruits. Ann. Appl. Biol. 98:79-85.

Quinones, W., Escobar, G., Echeverri, F., Torres, F., Rosero, Y., Arango, V., Cardona, G. and Gallego, A. 2000. Synthesis and antifungal activity of Musa phytoalexins and structural analogs. Molecules 5:974-980.

Simmonds, J. H. 1963. Studies in the latent phase of Colletotrichum species causing rots of tropical fruits. Qd. J. Agric. Sci. 20:373-424.

Tang, W., Zhua, S., Lia, L., Liua, D. and Irving, D. E. 2010. Differential expressions of PR1 and chitinase genes in harvested bananas during ripening, and in response to ethephon, benzothiadizole and methyl jasmonate. Postharvest Biol. Tec. 57:86-91.

Terry, L. A. and Joyce, D. C. 2004. Elicitors of induced disease resistance in postharvest horticultural crops: a brief review. Postharvest Biol. Tec. 32:1-13.

Trudel, J. and Asselin, A. 1989. Detection of chitinase activity after polyacrylamide gel electrophoresis. Anal. Biochem. 178:362-366.

Van Loon, L. C. 1997. Induced resistance in plants and the role of pathogenesis related proteins. Eur. J. Plant Pathol. 103:753765.

Yue-Ming, J. 1997. Incidence of anthracnose in relation to chitinase, $\beta$-1,3-glucanase and dopamine of banana fruits after harvest. Acta Photophysiol. Sinica 23:158-162.

Zou, X., Nonogaki, H. and Welbaum, G. E. 2002. A gel diffusion assay for visualization and quantification of chitinase activity. Mol. Biotechnol. 22:19-23. 